\title{
Evaluation of Nitrate Reductase Assay for Rapid Detection of Drug Resistant Tuberculosis
}

\author{
Ranjit Kumar Sah ${ }^{1 *}$, Dwij Raj Bhatta ${ }^{1}$, Gokarna Raj Ghimire ${ }^{2}$, Jeevan Bahadur Sherchand ${ }^{3}$ \\ ${ }^{1}$ Central Department of Microbiology, Tribhuvan University, Kathmandu, Nepal \\ ${ }^{2}$ National Tuberculosis Center, Bhaktapur, Nepal \\ ${ }^{3}$ Institute of Medicine, Tribhuvan University Teaching Hospital, Kathmandu, Nepal \\ Email: *ranjitkmrsah@gmail.com
}

Received October 15, 2012; revised November 25, 2012; accepted December 6, 2012

\begin{abstract}
Emergence of multidrug-resistant tuberculosis (MDR-TB) urgently demands for simple, rapid and inexpensive methods of its detection for the effective treatment of drug resistant tuberculosis, particularly in low-income countries. A total of 113 clinical isolates of M. tuberculosis were tested for four first line antitubercular drugs by nitrate reductase assay (NRA) and were compared with standard proportion method to evaluate NRA efficacy. Results were available in 7 - 14 days by NRA as compared to proportion method which generally takes $4-6$ weeks. The sensitivity and specificity of NRA were $98.1 \%$ and $100 \%$ for isoniazid, $95.1 \%$ and $98.6 \%$ for rifampicin, $91.4 \%$ and $94.9 \%$ for streptomycin, and $78.6 \%$ and $97.9 \%$ for ethambutol, respectively. Agreement between NRA and proportion method were 99.1\%, 97.3\%, $93.8 \%, 95.6 \%$ for isoniazid, rifampicin, streptomycin and ethambutol, respectively. NRA is easier, inexpensive and reliable method for susceptibility testing of Mycobacterum tuberculosis for isoniazid and rifampicin, the two most important drugs for the treatment of tuberculosis. The reduction in susceptibility testing time, and higher sensitivity and specificity of NRA method is of fundamental importance in detecting MDR-TB.
\end{abstract}

Keywords: Drug Susceptibility; MDR-TB; NRA; Proportion Method

\section{Introduction}

Emergence of multidrug resistant tuberculosis (MDR-TB) during the past ten years in higher rate represents a major public health problem, especially in low-resource countries where the burden of the disease is higher. MDR-TB constitutes a serious threat for the effective control of the disease stressing the need for the rapid detection of drug resistance [1]. Conventional methods like proportion method (PM), the resistance ratio method and the absolute concentration method to detect drug resistance in Mycobacterium tuberculosis have traditionally relied on slow and cumbersome procedures requiring a minimum of 3 4 weeks to produce results [2]. Other methods, such as the BACTEC 460 TB System [3], and oxidation-reduction dyes, e.g. tetrazolium [4], and Microplate Alamar Blue assay (MABA) [5], are faster but have the drawback of requiring either radioactive or expensive substrates, and are consequently not feasible in most resource-poor settings. A cost effective and rapid drug susceptibility method is required to guide TB treatment.

With similar characteristics to colorimetric methods, the nitrate reductase assay (NRA) has been described, which is based on the ability of $M$. tuberculosis to reduce

${ }^{*}$ Corresponding author. nitrate to nitrite after growth in the presence or absence of antibiotics. The use of specific reagents produces a change of color in the presence of nitrites indicating a positive result [6]. Since it is described around the globe as simpler, cheaper and rapid, evaluation of NRA as an alternative method for determining $M$. tuberculosis susceptibility to rifampicin (RIF), isoniazid (INH), streptomycin (STR) and ethambutol (EMB) in our laboratory setting which is technically insufficient is necessary.

\section{Material and Methods}

The NRA was performed on a total of 113 isolates of $M$. tuberculosis. Eighty three isolates were from cases reported for pulmonary TB at National Tuberculosis Center (NTC), Thimi, Bhaktapur, Nepal, between November 2009 and May 2010; and thirty isolates were of proficiency testing strain from Supranational Reference Laboratory, Germany.

The PM was carried out on Lowenstein and Jenson (LJ) medium according to the standard procedures with the recommended critical concentrations of $40 \mu \mathrm{g} / \mathrm{ml}$ for rifampicin, $0.2 \mu \mathrm{g} / \mathrm{ml}$ for isoniazid, $2 \mu \mathrm{g} / \mathrm{ml}$ for ethambutol and $4 \mu \mathrm{g} / \mathrm{ml}$ for streptomycin [2]. NRA was performed according to the already described protocol [6]. 
The following critical concentrations were used: 0.2 $\mu \mathrm{g} / \mathrm{ml}$ for INH, $40 \mu \mathrm{g} / \mathrm{ml}$ for RIF, $4 \mu \mathrm{g} / \mathrm{ml}$ for STR and $2.0 \mu \mathrm{g} / \mathrm{ml}$ for EMB. Briefly, fresh subculture (1 $\mu$ l loops of bacteria) from isolates of M. tuberculosis grown on LJ medium was taken and vortexed in small amount of sterile distilled water and turbidity was adjusted according to McFarland standard No.1. Part of the suspension was diluted 1:10 in sterile distilled water. For each isolate, 0.2 $\mathrm{ml}$ of suspension was inoculated into the tubes containing $\mathrm{LJ}$ medium with potassium nitrate $\left(\mathrm{KNO}_{3}\right)$ and the antitubercular drugs; $0.2 \mathrm{ml}$ of the 1:10 dilution was inoculated into drug free media (LJ media) containing $\mathrm{KNO}_{3}$ which served as growth controls. Tubes in triplicate were incubated at $37^{\circ} \mathrm{C}$ for 14 days and $0.5 \mathrm{ml}$ of a mixture of three reagents $(25 \mu$ of concentrated $\mathrm{HCl}, 50$ $\mu \mathrm{l}$ of $2 \%$ sulphanilamide and $50 \mu \mathrm{l}$ of $1 \% \mathrm{n}-1$-napthylethylenediamine dihydrochloride) was added to one drug free control tube after 7 days of incubation. If its colour changed to pink then tubes with drugs were tested. An isolate was considered resistant if there was colour change (pink or deep red to violet) in the drug tube in question greater than in the 1:10 diluted growth control on the same day. If the tubes did not show any colour change and remains the same, these were further incubated for 10 days and for 14 days as described [6]. Statistical analysis of data was carried out using $\chi^{2}$ test at $5 \%$ level of significance using Statistical Package for Social Science (SPSS version 17.0).

\section{Results}

Altogether $113 \mathrm{M}$. tuberculosis isolates were tested and the results were available in 7 days for $63.3 \%$ of the strains, in 10 days for $82.3 \%$ of the strains, and in 14 days for $100 \%$ of the strains by NRA method (Table 1). Of the total isolates, isolates showing resistance to INH, RIF, STR and EMB were 46.0\%, 36.3\%, 30.9\% and $12.4 \%$ respectively, by the proportion method while resistance to respective drugs was $45.1 \%, 35.4 \%, 31.8 \%$ and $11.5 \%$ by NRA. The sensitivity and specificity for NRA were $98.1 \%$ and $100.0 \%, 95.1 \%$ and $98.6 \%, 91.4 \%$ and $94.9 \%$, and $78.6 \%$ and $97.9 \%$ for INH, RIF, STR and EMB respectively (Table 2). The results showed that NRA and proportion method do not differ significantly ( $P>0.05$ for all the drugs). There was high agreement between both methods (Table 3) when tested against INH, RIF, STR and EMB with kappa, $\mathrm{k}=0.98,0.93$, 0.86 and 0.81 respectively.

\section{Discussion}

Traditional drug susceptibility testing such as the PM on LJ or agar medium is time consuming. For developing countries, it would be helpful to have a simple and inexpensive test that can rapidly detect resistant $M$. tuberculosis strains. The reporting time of NRA was between 7 14 days with majority in 10 days as against $28-42$ days for the conventional PM. This is very much comparable with the results of MGIT and BACTEC $460 \mathrm{~TB}$, which require the use of expensive instruments and high running cost. The rapidity with which test could be performed has also been reported with comparable accuracy to that of NRA such as the MTT or resazurin assays [7]. However, they make use of liquid medium in a microplate format and that makes the technique more complex and might also constitute a biohazard. Instead, the NRA utilizes standard solid LJ-medium, although with $\mathrm{KNO}_{3}$

Table 1. Number of days required for result by NRA method.

\begin{tabular}{ccc}
\hline No. of days & $\begin{array}{c}\text { No. of specimens } \\
\text { reported }\end{array}$ & Cumulative \% \\
\hline 7 & 56 & 63.3 \\
10 & 37 & 82.3 \\
14 & 20 & 100.0 \\
\hline
\end{tabular}

No: Number.

Table 2. Comparison of indirect nitrate reductase assay results with conventional proportion method.

\begin{tabular}{|c|c|c|c|c|c|c|c|}
\hline \multirow[b]{2}{*}{ Drugs } & \multirow{2}{*}{$\begin{array}{l}\text { Conventional } \\
\text { proportion } \\
\text { method }\end{array}$} & \multicolumn{6}{|c|}{ Nitrate reductase assay method } \\
\hline & & Resistant & Sensitive & $\begin{array}{c}\text { Sensitivity } \\
(\%)\end{array}$ & $\begin{array}{c}\text { Specificity } \\
(\%)\end{array}$ & $\begin{array}{c}\text { PPV } \\
(\%)\end{array}$ & $\begin{array}{c}\text { NPV } \\
(\%)\end{array}$ \\
\hline \multirow{2}{*}{ INH } & Resistant $=52$ & 51 & 1 & \multirow{2}{*}{98.1} & \multirow{2}{*}{100} & \multirow{2}{*}{100} & \multirow{2}{*}{98.4} \\
\hline & Sensitive $=61$ & 0 & 61 & & & & \\
\hline \multirow{2}{*}{ RIF } & Resistant $=41$ & 39 & 2 & \multirow{2}{*}{95.1} & \multirow{2}{*}{98.6} & \multirow{2}{*}{97.5} & \multirow{2}{*}{97.3} \\
\hline & Sensitive $=72$ & 1 & 71 & & & & \\
\hline \multirow{2}{*}{ STR } & Resistant $=35$ & 32 & 3 & \multirow{2}{*}{91.4} & \multirow{2}{*}{94.9} & \multirow{2}{*}{88.9} & \multirow{2}{*}{96.1} \\
\hline & Sensitive $=78$ & 4 & 74 & & & & \\
\hline \multirow{2}{*}{ EMB } & Resistant $=14$ & 11 & 3 & \multirow{2}{*}{78.6} & \multirow{2}{*}{97.9} & \multirow{2}{*}{84.6} & \multirow{2}{*}{97} \\
\hline & Sensitive $=99$ & 2 & 97 & & & & \\
\hline
\end{tabular}

PPV: Positive Predictive Value; NPV: Negative Predictive Value. 
Table 3. Percentage agreement between the proportion and the NRA methods for susceptibility testing of $M$. tuberculosis to each drug tested.

\begin{tabular}{lccc}
\hline & \multicolumn{2}{c}{ No. of isolates with the following results } & \\
\cline { 2 - 3 } Drugs & $\begin{array}{c}\text { PR method-susceptible } \\
\text { NRA } \\
\text { method-susceptible }\end{array}$ & $\begin{array}{c}\text { PR method-resistant } \\
\text { NRA } \\
\text { method-resistant }\end{array}$ & $\begin{array}{c}\text { Percent } \\
\text { agreement }\end{array}$ \\
\hline INH & 61 & 51 & 99.1 \\
RIF & 71 & 39 & 97.3 \\
STR & 74 & 32 & 93.8 \\
EMB & 97 & 11 & 95.6 \\
\hline
\end{tabular}

incorporated and it could therefore be easily adopted in any culture laboratory.

Nitrate reductase-negative strains of $M$. tuberculosis are very unusual [8] and on the other hand, false susceptible results would in this case be detected by the lack of a positive reaction also in drug free growth. M. bovis does not reduce nitrate, therefore the NRA technique is not applicable. Disadvantages of NRA are; the culture is killed by the mix reagent used to develop the assay, requiring that multiple cultures be prepared if comparative testing will be performed and only fresh cultures must be used ( $<14$ days).

In present study, a high level of agreement between NRA and PM was determined for isoniazid and rifampicin. However, despite a higher agreement between NRA and PM for streptomycin (93.8\%) and ethambutol (95.6\%), low sensitivity of streptomycin (91.4\%) and ethambutol (78.6\%) was found. For isoniazid and rifampicin, sensitivity and specificity was found to be high; $98.1 \%$ and $100.0 \%$, and $95.1 \%$ and $98.6 \%$ respectively. These results are very important since rifampicin and isoniazid are the two most important drugs used in the treatment of TB [9]. Higher accuracy results for INH, RIF and EMB and lower accuracy results for STR were shown in a similar multicenter study [10]. The percentage agreement of $98.3 \%, 98.3 \%, 90.8 \%$ and $93.3 \%$ by NRA for INH, RIF, STR and EMB respectively, were observed in Brazilian study [11]. However, marginally lower sensitivity and specificity for STR and EMB have also been reported [7,12]. For STR and EMB testing, performance differences were seen among different laboratories rather than drug sensitivity testing method which is argued as inherent difficulties of testing with these two drugs stressing the need for continuing participation in proficiency testing [13].

\section{Conclusion}

In the context of emergence of MDR-TB, the NRA may be of great importance due to its higher sensitivity and specificity for the rapid detection of rifampicin and isoniazid resistance, the two most important drugs for tuberculosis treatment

\section{Acknowledgements}

The authors acknowledge all the laboratory staffs of NTC and SAARC TB/HIV Center, for their worthy cooperation during the study.

\section{REFERENCES}

[1] J. A. Caminero, "Multidrug-Resistant Tuberculosis: Epidemiology, Risk Factors and Case Finding," International Journal of Tuberculosis and Lung Disease, Vol. 14, No. 4, 2010, pp. 382-390.

[2] G. Canetti, W. Fox, A. Khomenko, H. T. Mahler, N. K. Menon, D. A. Mitchison, N. Rist and N. A. Smelev, "Advances in Techniques of Testing Mycobacterial Drug Sensitivity and the Use of Sensitivity Tests in Tuberculosis Control Programmes," Bulletin of the World Health Organization, Vol. 41, No. 1, 1969, pp. 21-43.

[3] G. D. Roberts, N. L. Goodman, L. Heifets, H. W. Larsh, T. H. Lindner, J. K. McClatchy, M. R. McGinnis, S. H. Siddiqi and P. Wright, "Evaluation of the BACTEC Radiometric Method for Recovery of Mycobacteria and Drug Susceptibility Testing of Mycobacterium Tuberculosis from Acid-Fast Smear-Positive Specimens," Journal of Clinical Microbiology, Vol. 18, No. 3, 1983, pp. 689696.

[4] L. Caviedes, J. Delgado and R. H. Gilman, "Tetrazolium Microplate Assay as a Rapid and Inexpensive Colorimetric Method for Determination of Antibiotic Susceptibility of Mycobacterium tuberculosis," Journal of Clinical Microbiology, Vol. 40, No. 5, 2002, pp. 1873-1874. doi:10.1128/JCM.40.5.1873-1874.2002

[5] S. G. Franzblau, R. S. Witzig, J. C. McLaughlin, P. Torres, G. Madico, A. Hernandez, M. T. Degnan, M. B. Cook, V. K. Quenzer, R. M. Ferguson and R. H. Gilman, "Rapid, Low-Technology MIC Determination with Clinical Mycobacterium tuberculosis Isolates by Using the Microplate Alamar Blue Assay," Journal of Clinical Microbiology, Vol. 36, No. 2, 1998, pp. 362-366.

[6] K. A. Angeby, L. Klintz and S. E. Hoffner, "Rapid and Inexpensive Drug Susceptibility Testing of Mycobacterium tuberculosis with a Nitrate Reductase Assay," Journal of Clinical Microbiology, Vol. 40, No. 2, 2002, pp. 553-555. doi:10.1128/JCM.40.2.553-555.2002

[7] E. Montoro, D. Lemus, M. Echemendia, A. Martin, F. Portaels and J. C. Palomino, "Comparative Evaluation of the Nitrate Reduction Assay, the MTT Test, and the Resazurin Microtitre Assay for Drug Susceptibility Testing of Clinical Isolates of Mycobacterium tuberculosis," The Journal of Antimicrobial Chemotherapy, Vol. 55, No. 4, 2005, pp. 500-505. doi:10.1093/jac/dki023

[8] P. T. Kent and G. P. Kubica, "Pubic Health Mycobacteriology: A Guide for the Level III Laboratory," US Department of Health and Human Services, Public Health Service, Centers for Disease Control and Prevention, Atlanta, 1985, pp. 159-184. 
[9] World Health Organization, "The WHO/International Union against Tuberculosis and Lung Disease. Global Project on Anti-tuberculosis Drug Resistance Surveillance. Anti-Tuberculosis Drug Resistance in the World, Report No. 3," World Health Organization, Geneva, 2004.

[10] A. Martin, E. Montoro, D. Lemus, N. Simboli, N. Morcillo, M. Velasco, J. Chauca, L. Barrera, V. Ritacco, F. Portaels and J. C. Palomino, "Multicenter Evaluation of the Nitrate Reductase Assay for Drug Resistance Detection of Mycobacterium tuberculosis," Journal of Microbiological Methods, Vol. 63, No. 2, 2005, pp. 145-150. doi:10.1016/j.mimet.2005.03.004

[11] M. L. Shikama, R. R. Silva, M. C. Martins, C. M. Giampaglia, R. S. Oliveira, R. F. Silva, P. F. Silva, M. A. Telles, A. Martin and J. C. Palomino, "Rapid Detection of Resistant Tuberculosis by Nitrate Reductase Assay Performed in Three Settings in Brazil," The Journal of An- timicrobial Chemotherapy, Vol. 64, No. 4, 2009, pp. 794796. doi:10.1093/jac/dkp284

[12] D. Lemus, E. Montoro, M. Echemendia, A. Martin, F. Portaels and J. C. Palomino, "Nitrate Reductase Assay for Detection of Drug Resistance in Mycobacterium tuberculosis: Simple and Inexpensive Method for Low-Resource Laboratories," Journal of Medical Microbiology, Vol. 55, No. 7, 2006, pp. 861-863. doi:10.1099/jmm.0.46540-0

[13] A. Laszlo, M. Rahman, M. Espinal, M. Raviglione and the WHO/IUATLD Network of Supranational Reference Laboratories, "Quality Assurance Programme for Drug Susceptibility Testing of Mycobacterium tuberculosis in the WHO/IUATLD Supranational Reference Laboratory Network: Five Round of Proficiency Testing, 1994-1998," International Journal of Tuberculosis and Lung Disease, Vol. 6, No. 9, 2002, pp. 748-756. 